\title{
Industrial Trucks in
}

\section{the Age of Industry 4.0}

Dear Reader,

In the logistics sector too, Industry 4.0 is increasingly having repercussions in products and solutions. The fast development cycles, for example in sensor systems and image capturing, enable completely new automation solutions to be created. Today, industrial trucks must have the capability to communicate not only with persons but also with other machines and vehicles. Furthermore, they must be connected with the operator's ERP systems and ideally also with the vehicle manufacturers themselves. Ultimately, the aim of all this is to improve efficiency.

What such Industry 4.0 solutions might look like was demonstrated by the company Still at LogiMat, which took place at the beginning of March this year. With its new iGo neo CX20 order picker, the Hamburg-based company is the first industrial truck manufacturer to introduce a mobile robotics solution into intralogistics on a series-production basis, according to Still's CSO Thomas Fischer in our interview. The autonomous industrial truck interacts with the operator like a team member and adapts to his or her working rhythms. As the truck follows the operator at every turn, he or she can move freely around the truck and focus on order picking. Field tests have shown that the autonomous helper achieves a time saving of up to $30 \%$ compared to conventional vehicles and has much higher picking performance, as it significantly reduces the time spent getting on and off the truck. This interactive teamwork between man and machine is made possible by two laser-assisted motion tracking systems, whose sensor-assisted visual field enables the truck to react to its environment constantly in $360^{\circ}$ mode. They ensure that the truck can recognise oper- ators' intentions based on their movements and can interact with them. The order picker also convinced the jury of the "Best Product" LogiMat award. It won the prize in the category "Order-picking, conveying, lifting and warehouse technology”. What particularly impressed me at the press presentation of the truck on the evening before LogiMat was the way in which it relieves the stress on the driver, who can now focus entirely on the main job of order picking and is even given physical assistance.

As always, when one fair comes to an end, another is about to open its doors. And this also applies to manufacturers of industrial trucks. The next major fair CeMAT 2016 in Hanover (Germany) is scheduled for the end of May. I am sure that it will also showcase numerous innovations on the topic of Industry 4.0.

I hope to see you in Hanover.

Best regards,

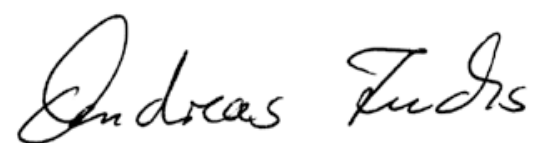

Andreas Fuchs

Chief Correspondent

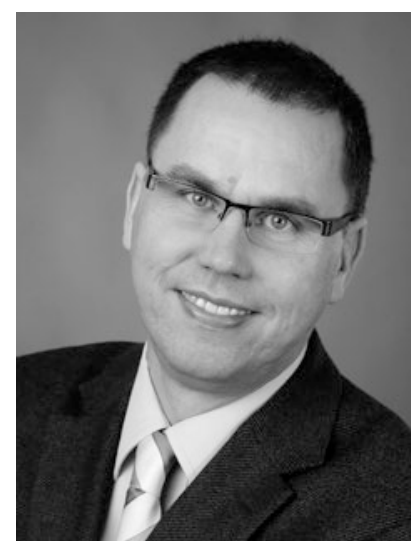

